\title{
SHOPPING CENTERS COMO ESPAÇOS DE CONSUMO E DE LAZER: O CASO DO MARINGÁ PARK E DO CATUAí SHOPPING DE MARINGÁ, PARANÁ, BRASIL
}

\author{
Josimari de Brito Morigi \\ Pós-Graduação em Sociedade e Desenvolvimento - Universidade Estadual do Paraná \\ josimorigi@gmail.com
}

\begin{abstract}
Resumo
O presente estudo tem como objetivo analisar a o papel dos shopping centers como espaço de consumo e de lazer com foco direcionado para o caso do Maringá Park e do Catuaí Shopping localizados na cidade de Maringá-PR. Para alcançar os objetivos propostos pela investigação foram adotados os seguintes procedimentos metodológicos: levantamento bibliográfico em livros, artigos teses e dissertações que versam sobre a temática que se propõe analisar neste ensaio teórico, e posteriormente realizou-se um trabalho de campo para verificar as principais características dos shoppings escolhidos para o estudo. O interesse pelo estudo destes shoppings destaca-se dentre outros motivos pelo papel que tais empreendimentos desempenham na funcionalidade urbana de Maringá, especialmente enquanto espaços de sociabilidade, e ainda pelo interesse de analisar quais agentes produtores do espaço urbano estão envolvidos nesses processos. O shopping center é considerado um dos principais símbolos do consumismo nos dias atuais, e está presente na grande maioria das cidades brasileiras, sobretudo, de grande e de médio porte. Ressalta-se que a intensificação na construção de shopping centers foi de certo modo beneficiada por novas conjunturas evidenciadas na geografia econômica contemporânea, as quais evidenciam que os aspectos da sociedade de mercado acabaram por inserir nos consumidores novos valores de consumo.
\end{abstract}

Palavras chave: Espaço urbano. Shopping Centers. Maringá Park. Catuaí Shopping.

\section{SHOPPING CENTERS AS SPACES OF CONSUMPTION AND LEISURE: THE CASE MARINGÁ PARK AND SHOPPING CATUAí MARINGÁ, PARANÁ, BRAZIL}

\begin{abstract}
This study aims to analyze the role of shopping centers as consumer and leisure area with focus directed to the case of Maringa Park and Catuaí Shopping located in Maringá-PR. To achieve the objectives proposed by the research the following methodological procedures were adopted: literature in books, articles, theses and dissertations that deal with the theme to be analyzed in this theoretical essay, and subsequently held a field study to verify the main characteristics malls chosen for the study.

Interest in the study of these malls stands out among other reasons for the role they play in such enterprises urban functionality of Maringa, especially as spaces of sociability, and yet the interest of analyzing which producers of urban space agents are involved in these processes. The shopping center is considered one of the main symbols of consumerism today,
\end{abstract}


and is present in most Brazilian cities, especially large and medium-sized. It should be noted that the intensification in the construction of shopping centers was somehow benefited from new situations evidenced in contemporary economic geography, which show that the aspects of market society eventually enter the new consumer consumption values.

Keywords: Urban space. Shopping Centers. Maringá Park. Catuaí Shopping.

\section{Introdução}

Muitas foram as transformações econômicas e sociais ocorridas nas últimas décadas, as quais resultaram numa nova forma de consumo. Muitos autores descrevem que na sociedade pós-moderna o consumo passou a apresentar uma certa "dimensão espiritual", e o mercado passou a ser chamado de "Deus mercado", e os shopping centers passaram a ser definidos como "a catedral das mercadorias". As marcas dos produtos que são comercializados nestes locais também passaram a ser vistas como algo relacionado a própria identidade do indivíduo, especialmente ligada ao emocional do ser. Neste contexto, o filósofo e sociólogo francês Jean Baudrillard, considerado um dos principais críticos da sociedade de consumo, explana que a marca é capaz de transformar o produto em signo-mercadoria. Ela reforça ou compõe a identidade e o amor-próprio de muitas pessoas que buscam no consumo âncoras emocionais. Portanto, pode-se dizer que a influência da marca vai muito além da simples designação do valor de utilidade de um determinado produto.

O modelo de shopping centers que conhecemos atualmente surgiu nos Estados Unidos na década de 1950, como estratégias comerciais que visavam atender uma grande quantidade de pessoas, ofertando diversas atividades comerciais aglomeradas em um único espaço. $\mathrm{O}$ grande visionário neste tipo de empreendimento foi o americano Victor Gruen que almejava oferecer à população um ambiente amplo com diversidade de lojas e produtos, com amplo estacionamento para que pessoas de todos os cantos da cidade, especialmente dos subúrbios fossem até o shopping fazer compras. Além disso, o espaço também teria praça de alimentação e locais de lazer e a temperatura do ambiente seria definida de acordo com as características do clima, ou seja, no verão os aparelhos de ar condicionado refrescavam o ambiente e no inverno faziam o inverso, deixando a qualidade térmica do ambiente agradável para os usuários. 
Ressalta-se que o primeiro protótipo de shopping center idealizado por Victor Gruen foi instalado na cidade de Edina que está localizada no estado americano do Minnesota, no ano de 1956 e com o passar do tempo, este tipo de empreendimento se espalhou pelos subúrbios de muitas cidades norte-americanas. Contudo, a máxima popularidade deste modelo de shopping center foi alcançada na década de 1990, quando foram inaugurados 19 deles no País (SOUZA, 2013).

No Brasil, o primeiro shopping center foi instalado na cidade de São Paulo, o mesmo foi nomeado de Iguatemi e foi inaugurado em 1966 e está em funcionamento até hoje. Na década de 1970, sete novos empreendimentos foram iniciados, mas, somente a partir de 1989 que houve um aumento considerável na construção de shopping centers no País. Dentre os principais motivos que desencadeou a construção de vários shoppings no Brasil destaca-se que muitas empresas tradicionais assim como as marcas renomadas perceberam que havia a interessante possibilidade e também a necessidade de se unirem num mesmo espaço com a finalidade de oferecer uma ampla variedade de produtos, serviços e entretenimento.

Salienta-se que o Iguatemi está localizado na Avenida Brigadeiro Faria Lima na cidade de São Paulo e inicialmente era composto por 75 lojas, direcionadas especialmente para uma clientela sofisticada e de alto poder aquisitivo. Além do mais, esse shopping procurava atrair os lojistas e consumidores da Rua Augusta, que possuía no início dos anos de 1960 as mais famosas griffes em seus espaços (PINTAUDI, 1989, p. 100).

Tomando por referência os estudos realizados por Ruiz (2004), ressalta-se que com o passar do tempo as características deste shopping se modernizou e o seu público alvo também. Atualmente conta com 388 lojas satélites e três lojas âncoras, quais sejam: a C\&A, as Lojas Americanas e o Pão de Açúcar.

De acordo com Pintaudi (1992), no Brasil os shoppings surgiram durante o período que marcou o desenvolvimento de monopólios da economia brasileira, representando uma tendência de atividades comerciais varejistas, que antes não concentravam poder econômico. Muito embora o País tenha alcançado um crescimento socioeconômico considerável no decorrer do tempo, ele continuou sendo um país de contradição, ou seja, enquanto a parcela maior da população é pobre, há uma parcela menor de população que concentra a riqueza em suas mãos. E os shopping centers foram criados especialmente para atender a essa minoria da população que possui maior poder aquisitivo. Sendo que a maior concentração destes 
empreendimentos, segundo dados da ABRASCE - Associação Brasileira de Shopping Centers, está situada nas cidades da Região Sudeste do País, especialmente nas cidades de porte médio e grande que apresentam forte crescimento urbano, industrial, econômico e populacional.

Ao realizar uma análise sobre a construção de shoppins centers no Brasil, é possível de observar que de acordo com os dados apresentados pela ABRASCE (2014), o País possui atualmente 511 shoppings distribuídos pelo seu território. No entanto, a grande maioria destes empreendimentos está concentrada na Região Sudeste que possui 284 shoppings, com destaque par os estados de São Paulo e do Rio de Janeiro com 170 e 63 shoppings, respectivamente. Sobre este fator, Pintaudi (1989) afirma que a concentração de shopping centers de forma mais proeminente nos estados do Rio de janeiro e de São Paulo, se justifica pelo fato de que esses dois estados possuem um grande contingente populacional, e também um grande mercado consumidor. Portanto, para o sucesso dos shopping centers não basta apenas ter um grande quantitativo de habitantes, também é imprescindível constituir-se num mercado com poder aquisitivo elevado.

Ressalta-se que nos dias de hoje a grande maioria das cidades brasileiras de grande e de médio porte já possuem shoppings dentro de seu espaço urbano, evidenciando de certa forma, a modernidade e o desenvolvimento econômico alcançado pelas mesmas.

Salienta-se que os principais motivos que impulsionaram esse aumento no número de shopping centers em várias cidades brasileiras, foram o próprio crescimento urbano e os fatores oriundos deste processo, a população também passou a exigir cada vez mais segurança, conforto, praticidade e agilidade. Ademais, alguns fatores tais como as características climáticas de determinadas cidades, também incentivaram o crescimento do segmento, pois com a inserção de aparelhos de ar condicionado o ambiente interno dos shoppings deixavam a temperatura agradável para os clientes. Portanto, a qualidade física e psicológica destes locais é o que os seus usuários buscam.

O objetivo central deste estudo é analisar o papel dos shopping centers como espaço de consumo e de lazer com foco direcionado para o caso do Shopping Maringá Park e do Catuaí Shopping localizados na cidade de Maringá-PR. Para alcançar os objetivos propostos pela investigação foram adotados os seguintes procedimentos metodológicos: levantamento bibliográfico em livros, artigos teses e dissertações que versam sobre a temática que se propõe 
analisar neste ensaio teórico, e posteriormente realizou-se um trabalho de campo para verificar as principais características dos shoppings escolhidos para o estudo. O interesse pelo estudo destes shoppings destaca-se dentre outros motivos pelo papel que tais empreendimentos desempenham na funcionalidade urbana de Maringá, especialmente enquanto espaços de sociabilidade, e ainda pelo interesse de analisar quais agentes produtores do espaço urbano estão envolvidos nesses processos.

Este artigo, além desta introdução, está constituído por três momentos principais, sendo que num primeiro momento, é feita uma discussão sobre os agentes produtores do espaço urbano, destacando o processo de verticalização e também a construção de grandes shopping centers. Num segundo momento tem-se o direcionamento da discussão para a análise do shopping center e de sua essência capitalista. E num terceiro momento o foco de análise está voltado para os dois shoppings escolhidos para o estudo. Por fim, apresentam-se as considerações finais deste artigo.

\section{Os Agentes Produtores do Espaço Urbano}

O espaço urbano, apreendido como produto engendrado pelas ações realizadas pela sociedade no transcorrer do tempo, apresenta-se uma incessante dinamicidade, isto é, está em constante desenvolvimento e modernização, refletindo as ações dos agentes sociais, as quais se encontram vinculadas aos escopos mercadológicos, uma vez que as cidades são consideradas ambientes excepcionais para a reprodução do capital, através do consumo de bens e mercadorias, carecendo de tal modo, de espaços específicos que possam ser utilizados para a consolidação de tal processo.

Conforme explana Corrêa (1995), a produção do espaço urbano não é um processo aleatório, pois acontece de forma induzida pelos agentes produtores do espaço urbano, dos quais podemos destacar os proprietários dos meios de produção, os proprietários fundiários, os promotores imobiliários, o Estado e os grupos sociais excluídos. Por conseguinte, o espaço urbano é considerado um produto social, decorrente de ações geradas por agentes que produzem e consomem o espaço.

A articulação entre os agentes supracitados, denominados de modeladores do espaço urbano permite, segundo seus múltiplos interesses, dar forma ao espaço da cidade também por meio do processo de verticalização urbana, que tem como principal objeto/mercadoria, o 
edifício composto por diversos pavimentos, simbolizando, ainda, status, modernidade e desenvolvimento. Sendo que os edifícios constituídos por diversos pavimentos são muitas vezes, construídos especialmente para abrigar atividades comerciais, tais como grandes shopping centers, como, por exemplo, o Shopping Center Italia localizado na cidade de Curitiba (PR) e o Evolution Shopping Park localizado na cidade de Recife (PE) ilustrados na figura abaixo.

Figura 1: Shopping Center Italia localizado na cidade de Curitiba (PR) (a esquerda) e o Evolution Shopping Park localizado na cidade de Recife (PE) (a direita).

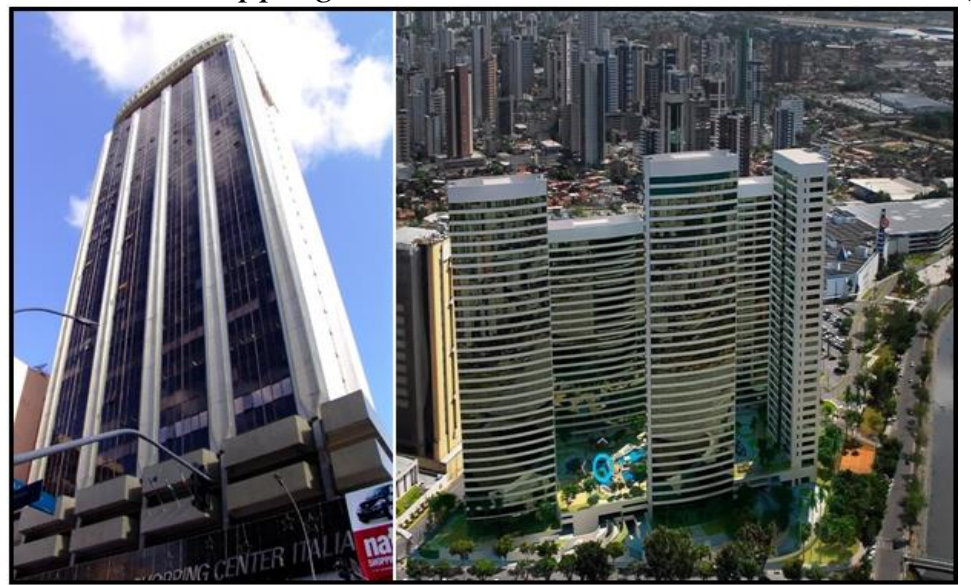

Fonte: http://www.skyscrapercity.com/showthread.php?t=294252> Acesso em 2 de Dez. de 2014. http://www.skyscrapercity.com/showthread.php?t=736268> Acesso em 2 de Dez. de 2014.

Conforme Souza (1989) e Oliveira (1992), de uma forma mais sucinta, são identificados ao menos três agentes que produzem a verticalização: os incorporadores, os construtores e os vendedores. Ademais, conforme salientam as autoras, o mesmo agente pode ostentar, pelo menos, duas incumbências, cujos papéis realizados podem ser agregados ou desagregados dependendo dos seus interesses.

Vale ainda ressaltar que o interesses dos agentes produtores do espaço urbano que produzem a verticalização estão interessados, sobretudo, em auferir lucros da forma mais eficiente possível. Neste contexto, Souza (1994) adverte que o espaço urbano se valoriza e sobrevaloriza através da instalação de edifícios verticais, visto que o processo de verticalização vai além da construção do edifício, possui a capacidade de reproduzir os diversos tipos de capitais. Compendiada na produção do edifício, a verticalização, na 
concepção de Souza (1994, p. 247), “[...] veio, sem dúvida alguma, realizar uma complexa estratégia do processo de produção capitalista na sua mais ampla dimensão [...].”

No que tange a (re) produção do espaço urbano cabe mencionar que a mesma ocorre dialeticamente, seja por meio da incorporação de novas áreas, seja pelo uso do solo, ou ainda, pela deterioração e/ou pela renovação urbana. A ação dos agentes e/ou atores da produção urbana, ainda que seja regulada pela legislação, vai refletir de algum modo o interesse dos detentores do capital. Habitualmente, com exceção dos grupos sociais excluídos, os demais agentes supramencionados são constituídos pela elite social e suas ações privilegiam os seus interesses.

Ghizzo e Asalin (2012) discorrem que há uma grande complexidade em se regular as ações dos proprietários dos meios de produção - representantes do capital e do Estado. Uma vez que, estes agentes geralmente solicitam alguns benefícios, tais como: terrenos amplos e de baixo custo, infraestruturas, redes de transporte, energia elétrica, etc., sempre em consonância à atividade desenvolvida. À vista disso, é muito comum estes agentes pleitearem junto ao Estado estes privilégios. No sistema capitalista, os proprietários dos meios de produção e do capital tendem a nortear a vida econômica e política das cidades e o Estado torna-se, de tal modo, instrumento desta classe.

Ainda de acordo com os autores, no que tange à produção de espaços designados às práticas de mercado e de consumo, como os shopping centers, por exemplo, as ações destes agentes também são consideráveis, pois se trata de espacialidades que exigem grandes investimentos em capital fixo como infraestruturas de transportes e comunicações, entre outros. Mesmo que sejam compostas de espaços privados que pertencem aos proprietários dos meios de produção, estas áreas geralmente acabam sendo beneficiadas por projetos destes agentes, de modo que possam acompanhar a evolução das práticas comerciais e também assegurar condições de reprodução e acumulação de capital aos investidores.

Ressalta-se que na sociedade pós-moderna, movida pelas imagens (HARVEY, 2007), as áreas urbanas destinadas especialmente para abrigar as atividades comerciais demandam grande quantidade de investimentos por parte dos agentes produtores do espaço urbano. Do Estado comumente são exigidos investimentos na modernização estrutural de um determinado local, neste ínterim podem ser incluídas as seguintes benfeitorias: ruas alargadas, estacionamentos, segurança, vias rápidas, terminais rodoviários, viadutos, entre outros. 
Lembrando que tais exemplos de infraestruturas podem proporcionar comodidade, praticidade e mobilidade à população. Por outro lado, a realização de investimentos por parte dos detentores do capital, investimentos estes que se encontram normalmente aliados às benfeitorias estatais, permitirão a reprodução do capital investido. Destarte, surge dentro do espaço urbano a produção de espaços de consumo como os shoppings. Todavia, os investimentos realizados pelos proprietários dos meios de produção, tanto nas áreas centrais, quanto nas áreas periféricas da cidade, se concretizarão excepcionalmente quando vierem acompanhados pelos investimentos concedidos pelo Estado.

No caso de Maringá, cidade onde está situado o Shopping Maringá Park e o Catuaí Shopping, espaços de análise deste estudo, observa-se que as transformações que têm ocorrido em seu espaço urbano, resultantes das ações do Estado e do capital privado, evidenciam como as ações destes agentes estão sempre em acordo com os interesses dos grandes investidores. Pois, conforme destaca Leitão (1999, p.46):

Esse segmento monopolista da burguesia vai procurar assegurar, na produção do espaço urbano, a defesa dos seus interesses, que seus representantes tendem a apresentar sob os mais diversos disfarces de interesse geral da sociedade, de benefício altruísta para todos os habitantes da cidade.

Diante do exposto, pode-se dizer que as ações do Estado, enquanto agente produtor do espaço urbano, habitualmente são engendradas de modo a obedecer aos interesses da elite, mesmo que se dê a impressão de que todos serão beneficiados com tais ações. Aliás, essa é a tática principal usada por eles, para ocultar os seus interesses por detrás de algo que supostamente serviria de benefícios para toda a população.

Todas as cidades apresentam dentro de sua malha urbana pontos de centralidade, os quais são identificados por meio de intensos fluxos de pessoas seja por razões de trabalho e/ou de consumo. Destarte, seu determinante é a convergência de fluxos materiais e imateriais, a exemplo dos dois shoppings situados em Maringá, objetos de análise neste estudo. Lembrando que, as centralidades podem apresentar aspectos temporais, ou seja, algumas centralidades podem se expressar somente durante a semana, enquanto outras se expressam somente nos finais de semana. Diante do exposto, verifica-se que a centralidade não ocorre apenas na área central da cidade. 
No que tange a centralidade desempenhada pelos shopping centers Spósito (1991) explana que:

Os shoppings centers são novas expressões da centralidade, pois são grandes equipamentos de consumo, que concentram atividades comerciais e de prestação de serviços, atraindo um grande número de consumidores. (SPÓSITO, 1991)

A mesma autora ainda destaca que "[...] a centralidade é entendida enquanto processo e o centro ou os centros como expressão territorial" materializada na cidade que admite a emergência de uma centralidade múltipla e complexa, no lugar da centralidade principal (SPÓSITO, 1996).

Desse modo, observa-se que a centralidade configura-se como um espaço de intensas relações sociais representadas, principalmente, nas atividades de mercado, sendo o comércio uma das relações mais importantes que se estabelece nas cidades.

Corroborando com o exposto, Ghizzo e Asalin (2012), ressaltam que as cidades caracterizam-se como os espaços mais favoráveis para as relações de troca. No transcorrer do tempo houve o desenvolvimento desta prática, especialmente para atender as demandas históricas da economia de mercado, e dentro deste contexto destaca-se a gênese dos shopping centers que ocorreu nos Estados Unidos, durante o século XIX. Contudo, estes empreendimentos apresentavam características bem distintas dos empreendimentos do tempo presente, de modo que as semelhanças tornam-se latente no aglomerado de atividades atreladas ao setor terciário. Portanto, o surgimento dos shopping centers marcou um importante momento de inovação do setor comercial urbano, haja vista que as lojas de departamento não estavam mais conseguindo atender às demandas e expectativas do público consumidor.

Sobre a gênese dos shopping centers, Villaça (2001) discorre que:

O shopping center é o sucessor da loja de departamentos, que por sua vez é a sucessora da loja geral, de meados do século XIX. Tem em comum o fato de basear-se na economia de aglomeração e na variedade de produtos que se complementam (VILLAÇA 2001, p. 303).

Ainda no que tange a gênese dos primeiros shoppings norte-americanos, cabe frisar que na concepção de Bienenstein (2002), o surgimento destes empreendimentos está relacionado com um contexto caracterizado pela concentração espacial do capital, que a partir da 
integração vertical dos processos de produção, comercialização e administração, tinha como intento a ampliação da reprodução do capital. Desta forma, pode-se dizer que os pressupostos que nortearam o surgimento dos shopping centers estão representados pela economia capitalista de aglomeração, que tinha como pretensão reduzir os custos e aumentar os lucros.

Já a difusão dos shopping centers tanto nos Estados Unidos, como em outros países, foi marcada pelo crescimento populacional que ocorreu nas cidades e, por conseguinte do crescimento que ocorreu nas próprias cidades. Além disso, o desenvolvimento tecnológico que possibilitou o uso de meios transportes mais flexíveis, também contribuiu para esse fenômeno, uma vez que possibilitou a desconcentração das atividades comerciais e de serviços que estavam concentradas nos centros principais. Destarte, conforme destaca Alves (2011), os shopping centers surgiram com a finalidade de atender a população que após a década de 1930, se descolou para as áreas suburbanas.

Neste ínterim ressalta-se que com o tempo houve o desenvolvimento das atividades comerciais que passaram a ganhar novas formas e conteúdos na própria ocupação do espaço urbano. Assim:

Os shopping centers evoluíram rapidamente, em virtude das suas potencialidades econômicas e de suas escalas de influência, transformandose tanto do ponto de vista das dimensões e forma de organização, quanto dos instrumentos de intervenção econômica e de articulação espacial nas grandes cidades (SANTOS JR., 1992, p. 62).

Muito embora os primeiros shopping centers tenham surgido ainda durante o século XIX, foi somente a partir de meados da primeira década do século XX que eles passaram a apresentar as principais características dos shopping centers que conhecemos nos dias de hoje.

Dentro deste ínterim, Ghizzo e Asalin (2012) afirmam que:

Em 1916, na periferia de Chicago, surgiu o Market Square, empreendimento que balizou de forma definitiva uma nova fase na organização espacial dos shoppings, proporcionando uma caracterização de empreendimento luxuoso e diversificado, sinal de status para o público frequentador, indo ao encontro da mudança de comportamento dos consumidores de uma sociedade de consumo que se instaurava (GHIZZO \& ASALIN (2012, p. 64).

A figura abaixo retrata a vista interna e externa do shopping village Market Square construído em Chicago em meados da primeira década do século XX. 
Figura 2: Visão interna e externa do shopping village Market Square em Chicago-EUA

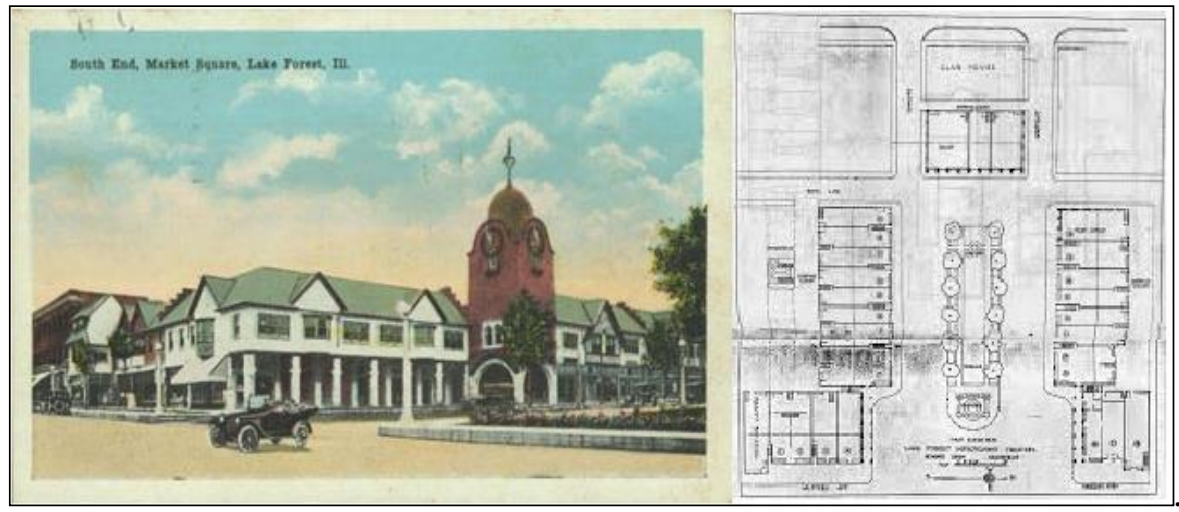

Fonte: http://sunnycv.com/steve/soc/shoppingcenter.html> Acesso em 01 dez. 2014.

Os mesmos autores ainda destacam que naquele mesmo período os shopping centers passaram a desenhar uma nova lógica no espaço urbano, pois os locais escolhidos para abrigálos deveriam ser de fácil acesso para a população. Destarte, priorizou-se a construção destes empreendimentos nas proximidades de rodoviárias e locais com fluxos rápidos, de forma a evitar que os seus frequentadores passassem por grandes congestionamentos ou tivessem dificuldades para encontrar estacionamento. Com isso, estes espaços tornaram-se muito atrativos para a população e também se tornaram muito interessantes para o mercado imobiliário, uma vez que, tais empreendimentos além de realizar intensas transformações na paisagem urbana, também proporcionam o desenvolvimento de obras que alteraram as áreas ao seu entorno, gerando uma valorização das mesmas e, de modo consequente, de uma produção espacial, ou ainda, em outros casos, uma revitalização da área em questão.

Sobre a influência exercida pelos shopping centers em suas áreas adjacentes Figueiredo (1997, p.1) explana que:

Os Shopping Centers são considerados o templo do consumo do mundo moderno. Para garantir o seu funcionamento e o lucro, atraem pessoas de distâncias variadas, tanto para trabalhar quanto para consumir ou para realizar as duas funções. Para conseguir tal intento, os shoppings criam vias de fluxo e áreas de influência, modificando assim o espaço ao seu redor.

Assim, vale enfatizar que a instalação de um shopping center em determinado bairro de uma cidade, acaba por gerar tanto no bairro onde este é implantado como também nas áreas ao entorno, diversos investimentos, tais como: a revitalização das infraestruturas e a instalação de novos empreendimentos comerciais. Deste modo, estas áreas adjacentes ao 
shopping tornam-se mais valorizadas e passam a receber investimentos da construção civil que constrói inúmeros prédios, com tamanhos e arquiteturas variadas, em suas proximidades, com o objetivo de obter lucro imobiliário.

Ademais, muitas vezes, também são realizadas modificações em algumas formas e/ou funções nos arredores do novo shopping center. Destarte, diversos terrenos, residências e/ou espaços comerciais que estavam até então vazios ou subutilizados passam a ser refuncionalizados, e muitos deles são utilizados para abrigar clínicas de odontologia, centros de beleza e estética, academias, escolas de idiomas, agências bancárias, etc.

Por fim, ressalta-se que este tipo de empreendimento também tem ganhado magnitude aos olhos do senso comum, como pode ser confirmado no discurso abaixo:

Em geral, o local escolhido ganha novas vias de acesso, mais rápidas, e passa a ser servido por mais transportes públicos. Essas vantagens atraem outros empreendimentos comerciais. A facilidade de consumo e acesso, por sua vez, torna a área convidativa para casas e prédios comerciais. Assim a região ganha não só novas feições, mas melhorias (Revista Veja, 1998, p. 77).

No entanto, é de suma importância a compreensão de que a construção dos shoppings não acontece de forma aleatória, pelo contrário, são planejadas com minúcia, visto que a construção de tais empreendimentos se mostra como um produto de um jogo de interesses dos agentes produtores do espaço urbano. Dentro deste contexto, Leitão (1999) ratifica que aos detentores dos meios de produção, que habitualmente agem em parceria com os promotores imobiliários e com o Estado, prima-se o interesse em desenvolver o espaço urbano organizando os investimentos privados no ambiente construído. Ademais, estes agentes realizam, de forma parcial ou total, operações como a incorporação e a gestão do capitaldinheiro a ser transformado em mercadoria; o financiamento a partir de recursos procedentes de pessoas físicas e jurídicas; o estudo técnico que averigua a viabilidade do empreendimento e, por fim, a construção do imóvel.

Geiger (2003) esclarece que dentre a produção do espaço urbano desempenhada pelos promotores imobiliários de Maringá, estão os shoppings, os quais representam uma produção material e imaterial, e uma simbologia alusiva à cultura das pessoas, gerada por forças que constroem e reconstroem o espaço urbano, numa reprodução da sociedade e do capital.

Cabe frisar que segundo Lefebvre (2001), as estruturas, as formas e as funções não se apresentam como elementos suficientes para dar conta de esclarecer a cerne do fenômeno 
urbano, mas sim a centralidade. Que se caracteriza como um elemento basilar para se apreender as mais diversas articulações que acontecem na cidade, pois atrai fluxos de trabalho e de consumo.

Em suma, é importante elucidar que a centralidade é expressa através das configurações e das funções do urbano, podendo ainda ser expressa de acordo com as características da mobilidade e da acessibilidade dos fluxos. Deste modo, ratifica-se que os dois shoppings situados em Maringá, selecionados para o estudo, assim como os demais shoppings existentes na referida cidade, influenciam na redefinição da estrutura da cidade e marcam a produção de uma centralidade urbana que atrai fluxos tanto da esfera local e regional, como estabelece uma rede que compreende a escala nacional.

No item seguinte deste artigo, pretende-se direcionar a discussão para a análise do shopping center e de sua essência capitalista.

\section{Shopping Center: a sua essência capitalista}

Nesta seção do artigo pretende-se analisar a essência capitalista do shopping center, uma vez que este tipo de empreendimento corresponde a um importante objeto que integra o conjunto de elementos relacionados ao processo de reorganização contemporânea do capital que por sua vez, tem transformado intensamente as cidades.

O shopping center é considerado um dos principais símbolos do consumismo nos dias atuais, ele está presente na grande maioria das cidades brasileiras de grande e de médio porte. Ressalta-se que a intensificação na construção de shopping centers foi de certo modo beneficiada por novas conjunturas evidenciadas na geografia econômica contemporânea, as quais evidenciam que os aspectos da sociedade de mercado acabaram por inserir nos consumidores novos valores de consumo.

Em seu livro: "Shopping Center: a Catedral das Mercadorias", Padilha (2006) discute a ideia de shopping center, destacando o objetivo principal destes empreendimentos, que é o de criar uma cidade perfeita, ou seja, uma cidade segurança, bonita, com boa iluminação, com conforto, limpeza e outros elementos, que possui várias opções de consumo, tornando-se um lugar ideal para encontros de uma sociedade distinta.

A autora também faz o leitor refletir sobre a complexidade das relações comerciais na sociedade contemporânea. Destacando o papel influente dos shopping centers no imaginário 
das pessoas, uma vez que os mesmos "fazem uso de poderosas armas" tais como a manipulação das necessidades e a publicidade, relacionando o consumo à ideia de alegria, de realização e de satisfação, e os shoppings ainda dão a entender que representam um espaço de construção de identidade, não somente lugar de compra de mercadorias.

Ainda de acordo com Padilha (2006, p. 30), o shopping center é “o mais capitalista centro de consumo, onde os desejos, os projetos, as paixões e as relações pessoais materializam-se em objetos a serem consumidos". Realmente, o shopping se constitui como o templo de consumo mais característico do capitalismo, pois quando se pensa em sua arquitetura sofisticada e bem elaborada e também nas estratégias físicas que suas lojas apresentam e que as tornam atrativas, pode-se entender que o shopping atua como um "predador" que usa suas artimanhas e captura suas "presas" sem ser perceptível, ou seja, fazendo exatamente o que o capitalismo espera dele: tornar os indivíduos consumidores e consumistas.

Portanto, o shopping center caracteriza-se como um fenômeno excepcional da sociedade capitalista global que tem o objetivo maior de transformar as pessoas em indivíduos adaptados ao consumo e ainda obsessivos pelo lucro. Nesse sentido, Padilha (2006) explana que os shopping centers estão sendo transformados em locais: de busca de realização pessoal pela felicidade do consumo; identificação ou não com grupos sociais; segregação mascarada pelo imperativo da segurança; enfraquecimento da atuação dos seres sociais e fortalecimento da atuação dos consumidores; materialização dos sentimentos; manipulação das consciências; homogeneização dos gestos, dos pensamentos e dos desejos, e o mais grave: ocupação quase integral do "tempo livre" das pessoas.

Nos dias de hoje, principalmente nas grandes cidades, o ir ao shopping representa bem mais do que uma simples necessidade de comprar, mas representa uma maneira de "fuga" das mazelas da cidade, pois enquanto a cidade é feia, é perigosa e às vezes insalubre, a "cidade" que existe no interior do shopping center é segura, é bonita e agradável. Nela as pessoas podem se esquivar da pobreza urbana. Em resumo, o shopping representa a "cidade ideal" para os citadinos e ao mesmo tempo representa o lugar do fetichismo do consumo.

Já nos estudos de Kelly (1955) e Hoyt (1958) apud Serpa (1991) é possível observar que os shoppings centers, e também os supermercados e hipermercados, são considerados as grandes inovações do comércio varejista. Todavia, os primeiros são amplamente debatidos 
nos centros acadêmicos, possivelmente porque consistem em "objetos" que conforme explana Bienenstein (2002, p.71) expressam "a reorganização contemporânea do capital, que por sua vez, tem transformado intensamente as cidades", ou seja, representam de forma concomitante empreendimentos comerciais e imobiliários.

Para contribuir com as discussões apresentadas neste artigo, torna-se necessário trazer à baila a definição de shopping center. Neste sentido, para Pintaudi (1992, p. 15-16), o shopping center é definido como:

[...] um empreendimento imobiliário de iniciativa privada que reúne, em um ou mais edifícios contíguos, lojas alugadas para comércio varejista ou serviços. Distinguem-se umas das outras não somente pelo tipo de mercadoria que vendem (o tenant mix planejado pela empresa prevê a presença de várias lojas do mesmo ramo para permitir a compra por comparação), como também por sua natureza distinta (lojas âncoras e lojas de comércio especializado e serviço - que podem ou não pertencer a redes). A estrutura e funcionamento do empreendimento são controlados por um setor administrativo, necessário para o funcionamento eficaz do shopping center, o que significa dizer que é o setor, cuja responsabilidade é zelar pela reprodução do capital da empresa. Além disso, está a presença de um parque de estacionamento, cujo tamanho se encontra na dependência do porte do empreendimento e de sua localização. Historicamente, é um fenômeno característico das sociedades capitalistas monopolistas (ainda que não necessário) (PINTAUDI, 1992, p. 15-16).

Ressalta-se que a partir desta definição apresentada pelo autor, pode-se pressupor que para a existência dos shopping centers deve haver a ação da iniciativa privada, a prática de locação das lojas à comerciantes, a combinação de diversas lojas, havendo ainda a necessidade da ocorrência do papel de âncora de algumas lojas e da disponibilidade de estacionamentos.

É importante ressaltar que conforme supramencionado os shopping centers são empreendimentos direcionados, sobretudo, para um mercado consumidor de alto poder aquisitivo. Sendo assim, representam símbolos de segregação socioespacial.

Santos (1994) complementa a reflexão acima ao destacar que:

Os mais pobres, pelo seu baixo poder aquisitivo, têm menos acesso às formas modernas de comercialização, que exigem dinheiro líquido ou crédito formal. Sua localização na cidade também reduz essa acessibilidade. Utilizam-se, assim de circuitos menos modernos e menos capitalistas de distribuição e freqüentemente recorrem às formas mais simples, que incluem vendas a crédito informal, o conhecido "fiado", que não desaparece da 
cidade porque nela os pobres não param de se instalar (SANTOS, 1994, p. 101-102).

Ademais, as próprias cidades brasileiras, se mostram cada vez mais fragmentadas, ou seja, com o desenvolvimento das atividades comerciais, industriais e com o crescimento demográfico a cidade foi sendo dividida em partes. A própria legislação municipal contribuiu para isto através da chamada lei do zoneamento urbano, onde a malha urbana é mapeada e "dividida em partes" para definir quais tipos de atividades (comerciais, industriais, residenciais) podem ser desempenhadas em cada uma destas áreas.

Sobre este assunto, Santos Junior (1992) discorre que:

Com o desenvolvimento das cidades acelerou-se a separação entre as suas partes. As áreas comerciais, residenciais industriais, de lazer etc., tornam-se cada vez mais definidas. A atividade das diferentes classes sociais vai criando internamente tecidos especiais, marcas na disputa que vai recortando territorialmente a cidade. Os SC tornaram-se, no interior desse processo, herdeiros diretos dos empreendimentos comerciais e imobiliários que demarcaram os signos de modernidade, desde o final do século passado nas grandes metrópoles capitalistas: as galerias, as lojas de departamento e os grandes edifícios comerciais (SANTOS JUNIOR, 1992, p.62).

Vale destacar que essa "fragmentação" da malha urbana, no que diz respeitos às suas funcionalidades, está concatenada com a mobilidade, isto é, com o uso do automóvel que permitiu o deslocamento das pessoas para qualquer área da cidade, assim como o deslocamento territorial dos equipamentos comerciais e de serviços no interior das cidades. Por conseguinte, ocorreu uma "fragmentação" da cidade em diversas porções para o consumo, para o lazer, para a sociabilidade e para a moradia.

Segundo Generoso (2009), o shopping center apresenta-se no cenário urbano brasileiro como um símbolo onipresente de poder. Tais empreendimentos caracterizam-se como "representação de um novo templo social, voltados para a criação de um universo de fantasia dirigido para o consumo" (GENEROSO, 2009).

Ainda de acordo com a autora, podem ser encontrados diversos tipos de lojas dentro de um shopping, tais como: agências bancárias, academias de ginástica, espaços de estética, cursos, entre outros. Assim sendo, vale enfatizar que a inserção de diversos serviços dentro do espaço dos shopping centers foi, sem sombra dúvida, uma mudança simples, mas que teve uma grande repercussão, uma vez que esses centros comerciais passaram a configurar 
verdadeiros centros urbanos, o que obviamente, coloca em questão a noção do público e do privado.

Neste sentido, o shopping center configura-se como um espaço privado, mas que se apresenta como público, dando a sensação ilusória às pessoas de que é uma nova cidade, porém, mais limpa, mais tranquila, mais bela, mais moderna, mais sofisticada, mais confortável e segura, com a escopo de atrair consumidores tanto de bens materiais e serviços, como também de lazer e entretenimento. Entretanto, esta "nova cidade" mostra-se excludente na medida em que é direcionada especialmente para um público com alto poder aquisitivo, e impede aqueles que não possuem os mesmos recursos de frequentar tais espaços e de consumir os produtos e serviços ali comercializados.

No entendimento de Generoso (2009), o shopping center pode ser classificado como uma nova cidade do capital. Ao passo que uma parcela da população cultua mercadorias e pode desfrutar de lazeres mais ostensivos, a outra parcela da população não possui sequer o acesso real a estes locais, e acaba tendo que se contentar com o anseio de um dia poder frequentar um hopping. Desse modo, o shopping, enquanto espaço urbano do capital é entendido como um espaço de contradições e de segregação social, na medida em que reflete a sociedade.

A forte segurança instalada na entrada dos shopping centers impede a entrada dos "indesejados" naquele ambiente, ou seja, os pobres, os "trombadinhas" e as prostitutas são impedidos de entrar. Além disso, a própria desigualdade na distribuição de renda acaba por inibir o poder de compra de muitas pessoas, sobretudo, nestes centros de consumo.

Além disso, o papel da publicidade também contribui para o aumento do consumo, e ainda colabora para as mudanças no padrão de consumo, especialmente por meio da propaganda televisiva que atinge todas as camadas da população. Geralmente, passa-se aos espectadores a impressão de que aquele produto que está sendo anunciado é único, exclusivo para quem o adquirir, porém, ao mesmo tempo a propaganda dá a entender que é preciso adquirir aquele produto, para a pessoa poder ser igual aos outros. Isto é, para ela não ser excluída. Portanto, as marcas são utilizadas como símbolos manipuladores pela publicidade para que a sociedade de consumo seja perpetuada, e isto depende de certo modo, da capacidade de criar novas necessidades para as pessoas e mais do que isso, manipular os seus desejos e necessidades, ou em outras palavras manipular os seus "sonhos sociais". Assim, a 
publicidade conforme descreve Padilha (2006) "é a grande responsável pela predominância das marcas sobre os produtos, ou seja, dos símbolos sobre as mercadorias"

Em suma, destaca-se que o valor simbólico das mercadorias e de suas marcas acaba provocando nas pessoas a necessidade de adquirir determinado bem, que seja de determinada marca, uma vez que o que prevalece atualmente no mundo do consumo é a aparência e o uso de certos bens como sinal de caráter e status social. Todavia, no sistema capitalista, o acesso ao consumo, considerado um dos elementos principais do imaginário urbano contemporâneo, e o abastamento serão sempre para a população de menor poder aquisitivo, algo ilusório, inalcançável, mas aos que compõe a classe média, ainda resta a esperança de um dia poder ter um poder aquisitivo que lhe permita consumir tais produtos.

Nos itens seguintes deste artigo, a análise está voltada especialmente para os dois shoppings escolhidos para o estudo, visando identificar o papel de ambos, como espaços de consumo e de lazer e a centralidade desempenhada por eles no espaço urbano maringaense.

\section{Shopping Maringá Park}

O Maringá Park Shopping Center (Figura 3), antigo Shopping Aspen Park, foi inaugurado no mês de abril de 1996 e está situado na Avenida São Paulo, entre as ruas Santos Dumond e Néo Alves Martins, no centro de Maringá-PR. Considerado o primeiro maior shopping da cidade, o mesmo possui um espaço amplo, com aproximadamente 30 mil metros quadrados.

Figura 3: Vista parcial da fachada e da área interna do Maringá Park

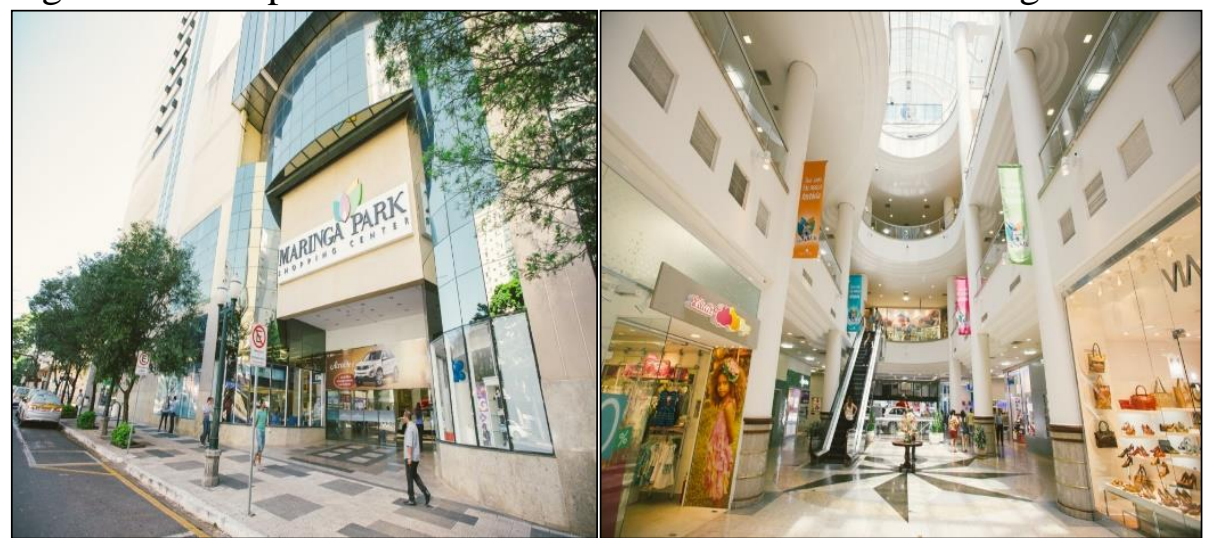

Fonte: Site do Maringá Park, 2014. 
Ressalta-se que a mudança de nome deste empreendimento ocorreu no ano de 2008, quando o empreendimento até então estava com 12 anos de existência e com o nome de Shopping Aspen Park, foi adquirido pela Nacional Shopping que pertence a um grupo de empresários com negócios na América Latina. A partir desse momento o empreendimento passou a se chamar Maringá Park e recebeu algumas reformas no seu exterior e no seu interior, passando a apresentar maior sofisticação e modernidade. Vale frisar que o processo de revitalização deste shopping incluiu a expansão de sua área física, a criação de novas salas de cinema, a renovação da fachada e a ampliação do estacionamento. Além do mais, as Lojas Renner passaram a ser uma das suas lojas âncoras, juntando-se a Riachuelo, Adidas, McDonald's, C\&A, Morena Rosa, entre outras.

Atualmente o Maringá Park possui aproximadamente de 95 lojas e 4 salas de cinema distribuídas pelos seus quatro andares e também dispõe de vários tipos de serviços (Achados e Perdidos; Pet Shop, Sapataria e Costura do Futuro; Lavagem Automotiva; Estacionamento Vip Estapar; Estacionamento Estapar; Casa de Câmbio; Cantinho Maringá Park; Caixas Eletrônicos e Saúde e Beleza) para melhor atender o seu público consumidor.

Considerado um shopping de porte médio, procura atender as tendências globais de modelo de shopping center, tanto no que se refere à diversificação de suas lojas, de seus serviços, como também pela incessante busca pela excelência no atendimento. Possui uma localização estratégica, facilitando o acesso das pessoas e ofertando a elas um espaço confortável, seguro, moderno, com ampla área de lazer e estacionamento. Salienta-se que neste shopping é comum a realização de exposições artísticas e culturais proporcionando uma ampliação de atrações para públicos diversos.

No entanto, por possuir em seu interior uma predominância de lojas de marcas famosas e de grifes, este shopping, igualmente a grande maioria dos shoppings brasileiros, acaba "afastando" a população que possui um menor poder aquisitivo.

Em suma, ressalta-se que a sua construção na área central da cidade, assim como a construção de outros empreendimentos, tais como o Shopping Avenida Center, fomentaram a centralidade nesta região da cidade e também denotam a realização de investimentos em construções e reformas por parte dos agentes da produção do espaço urbano com o objetivo de 
adequar a cidade às transformações urbanas mais atuais e, conseguintemente, criar condições de aumentar a reprodução e a acumulação de capital investido.

\section{Catuaí Shopping Maringá}

O Catuaí Shopping Maringá (Figura 4) foi inaugurado em 18 de novembro de 2010 na cidade de Maringá-PR, sendo mais um dos empreendimentos do grupo Catuaí de LondrinaPR. Possui uma localização estratégica, situando-se no entroncamento da BR 376 com a PR 317, principal ligação da cidade de Maringá com as regiões oeste e sul do estado. Seu acesso é considerado rápido e fácil tanto pela Avenida Colombo como pela Avenida Brasil, exceto nos chamados "horários de pico", quando o transito fica mais lento.

Figura 4: Vista aérea do Shopping Catuaí Maringá.

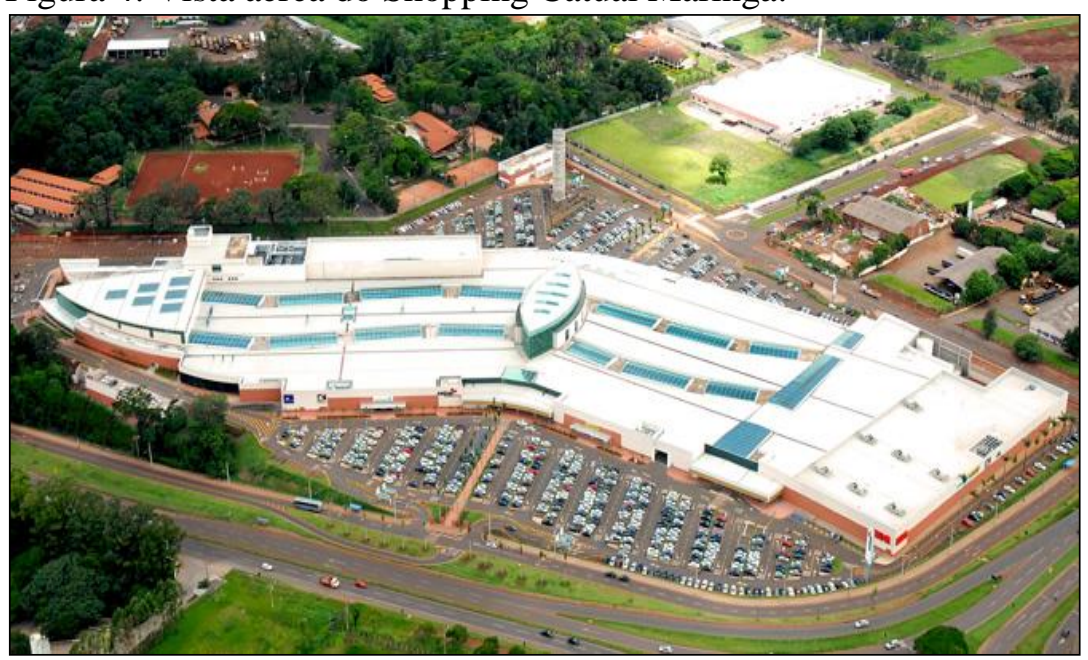

Fonte: Site do Shopping Catuaí Maringá, (2014).

De acordo com o Glossário Multiplan (2011) as lojas com mais de mil metros quadrados, denominadas de âncoras, são aquelas que são mais conhecidas pelo público, portanto, acabam atraindo um número maior de consumidores de todas as classes sociais, assegurando trânsito uniforme dos mesmos em todas as áreas do shopping center.

No Catuaí Maringá (Figura 5) existem oito lojas que se enquadram no conceito âncora e semi âncora, as quais são: Centauro, Havan, Hipermercado BIG, Lojas Colombo Premium, Magazine Luiza, Pernambucanas, Ri Happy e Riachuelo. Estas lojas de maior renome são permeadas por 184 lojas pequenas destinadas ao comércio em geral, denominadas Satélites. 
Figura 5: Localização das Lojas do Catuaí Maringá.

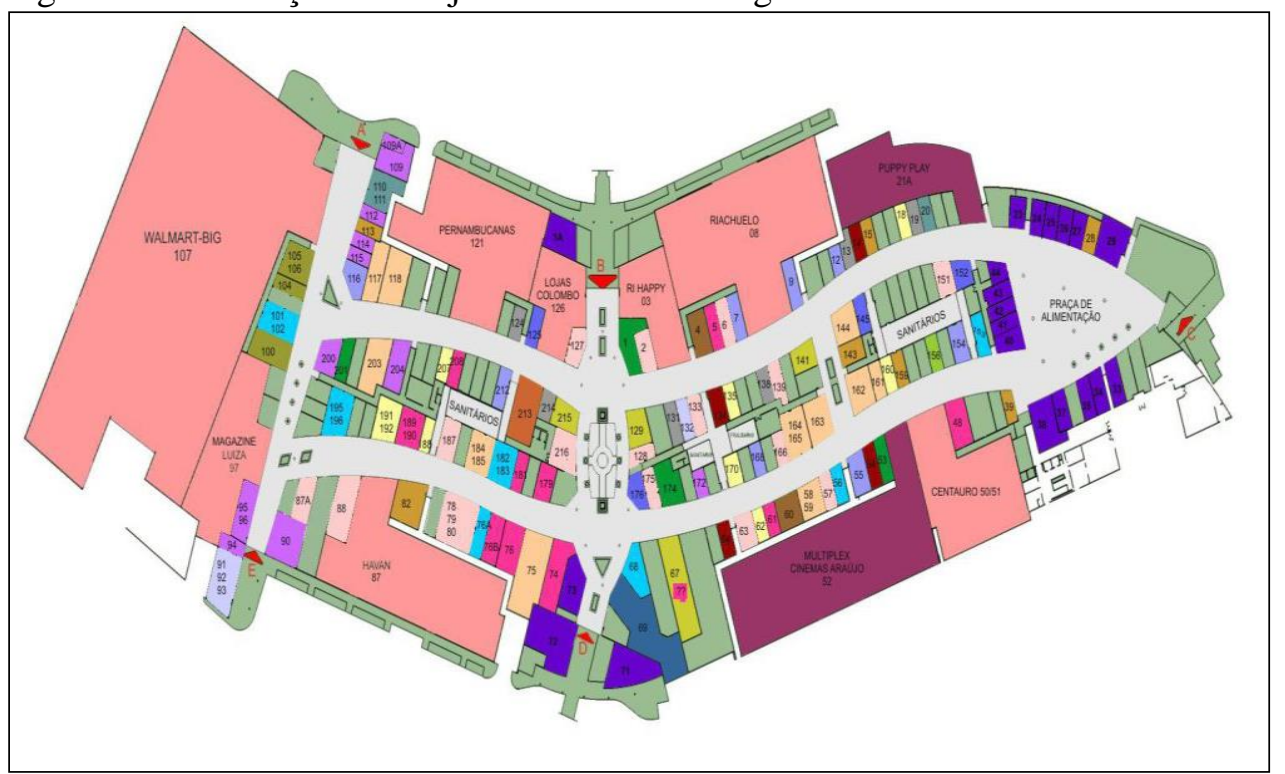

Fonte: Barbiero (2011).

Na figura 5 se pôde observar a localização das lojas que estão em funcionamento no Catuaí Maringá, sendo que as lojas mais renomadas possuem um espaço mais amplo. Ademais, as lojas existentes neste shopping distinguem-se umas das outras não apenas pelo tipo de mercadoria que comercializam (lembrando que o mix planejado pela empresa considera a presença de diversas lojas do mesmo ramo para permitir que os consumidores realizem a compra por comparação), como também por sua natureza distinta (lojas âncoras e semi- âncoras e lojas de comércio especializadas e de serviços).

Conforme explana Barbiero (2011), dentre as lojas existentes dentro do Catuaí, o setor de restaurantes e fast foods foi o que o que apresentou resultados mais positivos. Por outro lado, o setor de moda unissex/jovem foi o que apresentou resultados mais negativos. Contudo, salientase que algumas das primeiras lojas que foram instaladas neste shopping já não estão mais lá. Isto ocorreu porque as expectativas com relação a conquista de um percentual significativo de público consumidor não foi alcançado. E por não obter o desempenho e a lucratividade desejada, estas lojas encerraram suas atividades. No entanto, algumas destas lojas instaladas no Catuaí que inicialmente não foram bem aceitas pelo público, resolveram investir em mudanças para tentar atrair o público almejado, e as mudanças renderam bons resultados e elas continuaram na ativa. Também houve o fato de que algumas lojas que tinham sido anunciadas nas campanhas de lançamento do Shopping, ao menos chegaram a ser inauguradas. 
Ademais, conforme informações apresentadas no site do Catuaí há algumas lojas que estão para serem inauguradas nos próximos meses.

A tabela abaixo apresenta de forma resumida, as principais informações sobre este shopping.

Tabela 1: Shopping Catuaí Maringá, em números

\begin{tabular}{cccc}
\hline Área construída & $53.728,62 \mathrm{~m}^{2}$ & Restaurantes & 4 \\
\hline ABL & $33.450,66 \mathrm{~m}^{2}$ & Fast Food & 23 \\
Âncoras & 5 & Lojas de Serviços & 14 \\
Megalojas & 2 & Vagas de Estacionamento & 1462 \\
Centro de Diversões & 1 & Hipermercado & 1 \\
Cinemas & 5 salas & Satélites & 184 \\
\hline
\end{tabular}

Fonte: Site do Shopping Catuaí Maringá, 2014.

Adaptado pela autora.

Conforme a tabela acima, o Catuaí Maringá possui uma ABL (Área Bruta Locável) de mais de 33 mil metros quadrados, que corresponde ao somatório de todas as áreas disponíveis para locação dentro de um shopping center. A diversidade de lojas e as formas de lazer têm sido muito atrativas para a população local e regional que representam os principais frequentadores deste shopping. Apesar do espaço amplo e bem estruturado, observou-se durante o trabalho de campo que nos finais de semana as vagas disponibilizadas no estacionamento, muitas vezes se mostram insuficientes para atender o volume de carros, haja vista que nos finais de semana geralmente o público frequentador do shopping chega a ser de quatro a cinco vezes maior do que durante os demais dias da semana.

De acordo com as informações apresentadas no site do Catuaí Maringá (2014), este empreendimento possui também um centro de ensino FGV - Fundação Getúlio Vargas, possui áreas verdes internas, luz natural e um conceito de sustentabilidade e qualidade de vida. E é o segundo maior shopping do interior do Estado, ficando atrás do Catuaí Londrina.

Segundo Barbiero (2011), o Catuaí Shopping Maringá é um dos maiores centro de compras e lazer da região de Maringá e faz parte do portfólio da BRMALLS, que atualmente é considerada a empresa de maior presença no Estado do Paraná, em número de Shopping Centers. Pertencente ao grupo Catuaí, o Shopping Center Catuaí de Londrina, bem como o Shopping Catuaí Maringá foram idealizados e construídos pelo engenheiro civil Alfredo Khouri (que é também presidente do Grupo) em parceria com o arquiteto Carlos Alberto 
Domingues e o planejador Bernardo Kaplan. Muito embora esses dois Shoppings sejam as maiores bandeiras do grupo, ele também tem se dedicado a construções em vários ramos da engenharia civil como: edificações comerciais, residenciais, industriais, obras públicas, habitação social, entre outros.

Ainda de acordo com a autora, o termo Catuaí é de origem Tupi-Guarani e significa “ótimo", "muito bom". Lembrando que o nome Catuaí está relacionado a uma característica de regionalização com o Norte do Paraná, pois esse mesmo termo é utilizado para nomear uma variedade de café predominante nessa região.

Salienta-se que apesar do Catuaí ser um shopping direcionado inicialmente para atender a um público consumidor de todas as classes sociais, atualmente a grande maioria das lojas existentes no seu espaço são de marcas famosas e de grifes, destinadas ao consumo quase que exclusivo de uma classe que possui um poder aquisitivo mais elevado. $\mathrm{O}$ que acaba excluindo uma camada da população de consumir neste shopping. E, por conseguinte, prejudica o desempenho das demais lojas que não comercializam produtos de marcas famosas e de grifes.

Isto de certa forma vem ao encontro do pensamento de Pintaudi e Frugóli (1992), que afirmam que os shopping centers são "templos" que não foram construídos para a grande maioria da população, mas foram construídos para as poucas pessoas que estão situadas em estratos econômicos mais elevados.

Tratando-se especificamente do shopping center, o perfil sócio-econômico dos seus frequentadores que de certo modo já é "pré-definido" ainda durante o processo de planejamento do empreendimento, torna-se de suma importância, por se tratar de um ambiente que é construído não somente para levar a sociedade a possibilidade de consumo, mas também a segurança e principalmente o lazer.

\section{Considerações Finais}


Este artigo pretendeu apresentar uma análise sobre o papel dos shopping centers enquanto espaço de consumo e de lazer, elencando a sua representação simbólica enquanto “catedral das mercadorias", refletindo a cultura de consumo e o capitalismo atual.

As pessoas geralmente buscam a felicidades através da materialização dos sentimentos, dos desejos e do prazer, e isto faz com que as pessoas vejam no ato de consumir uma forma de realização e de satisfação de seus desejos, de suas carências e aspirações, e também como uma forma de "fuga" de suas frustrações e de suas angústias. E os shoppings são representados no imaginário das pessoas como um lugar de sonhos, de fantasias, enfim, um lugar bonito e mágico. Ademais, os shoppings representam um modelo de "cidade ideal", onde as pessoas podem "fugir" das mazelas da cidade e se sentir mais seguras, mais confortáveis e mais felizes.

Neste artigo também foi possível perceber que o estudo da centralidade criada pelos shopping centers nas cidades onde eles estão inseridos é de suma importância, sobretudo, para a ciência geográfica, pois permite uma ampliação nas possibilidades de investigação da dinâmica do desenvolvimento urbano local e regional e possibilita uma análise mais objetiva sobre os benefícios do desenvolvimento do setor terciário, no qual se integra os shopping centers, para as cidades.

No caso dos dois shopping centers abordados neste estudo, pode-se observar que ambos exercem fortes centralidades, apesar do Maringá Park estar situado na área central da cidade e o Catuaí Maringá estar localizado numa área bem longínqua ao centro da referida cidade.

Cabe ainda destacar que as múltiplas transformações que ocorreram no setor terciário de Maringá serviram também de atrativos para instalação de alguns shopping centers na cidade, dentre eles os dois shoppings analisados neste artigo.

Em suma, ressalta-se que a proposta dos shopping centers, em oferecer aos seus frequentadores um local seguro, com uma gama de lojas e de serviços, com amplo estacionamento e uma facilidade para se encontrar tudo no mesmo lugar, aliada a ideia de modernidade e progresso, foram os maiores atrativos para a grande maioria das pessoas definirem esses empreendimentos como lugar privilegiado para compras, lazer e entretenimento.

Por fim, ressalta-se que este estudo teve como finalidade contribuir para as discussões sobre o papel dos shopping centers na sociedade contemporânea, com foco direcionado para 
dois shoppings situados na cidade de Maringá. No entanto, adverte-se que são diversas as questões que ainda não foram resolvidas/respondidas, ficando nítida a necessidade de investigações de caráter mais aprofundado.

\section{Referências}

ABRASCE - Associação Brasileira de Shopping Centers. 2014. São Paulo, SP. Site institucional. www.abrasce.com.br. Acesso em Nov. de 2014.

ALVES, Lidiane Aparecida. Reestruturação Urbana e Criação de Novas Centralidades: considerações sobre os shoppings centers. In: Caminhos de Geografia. V. 12, n. 37, p. 171184, Março de 2011.

BARBIERO, Laís Carla da Silva. Relação do Consumidor com o Shopping Center- estudo de caso do Catuaí Shopping Maringá. In: Geoingá. V. 3, n. 2, 37-55, 2011.

BIENENSTEIN, Glauco. Shopping Center: O fenômeno e sua essência capitalista. In:

GEOgraphia, Ano 3, n. 6, p. 71-98, Dezembro de 2002.

CORRÊA, Roberto Lobato. O Espaço Urbano. São Paulo: Ática, 1995.

FIGUEIREDO, Simone da Silva. O espaço de inserção dos shopping Centers no município do Rio de Janeiro. Monografia de Graduação, Universidade Estadual do Rio de Janeiro, 1997.

GEIGER, Pedro Pinchas. As Formas do Espaço Brasileiro. Rio de Janeiro: Jorge Zahar Editora, 2003.

GENEROSO, Évelin. Shopping center: espaço de sociabilidade, wspaço de contradições. In: $\mathbf{1 2}^{\mathbf{0}}$ Encontro de Geógrafos da América Latina (EGAL), Montevideo, 2009.

GHIZZO, Márcio Roberto. ASALIN, Gilmar Aparecido. A Centralidade dos Shoppings de Confecções em Maringá-PR. In: Observatorium: Revista Eletrônica de Geografia. V. 3, n. 9, p. 57-78, abril de 2012.

HARVEY, David. Condição pós-moderna: uma pesquisa sobre as origens da mudança cultural. Trad. Adail Ubirajara Sobral, 16a edição. São Paulo: Loyola, 2007.

LEFEBVRE, Henri. O Direito a Cidade. Trad. Rubens E. Frias. São Paulo: Centauro, 2001.

LEITÃO, Gerônimo. Os Agentes Privados Envolvidos na Produção do Espaço Urbano. In Construção do Eldorado Urbano. Niterói, EDUFF, 1999. 
MULTIPLAN. Glossário. Lojas âncoras. 2011. Disponível em: <http://multiplan.infoinvest.com.br/static/ptb/glossario.asp?language=ptb $>$ acesso em $20 \mathrm{de}$ Nov. de 2014

OLIVEIRA, Janete Marília Gentil Coimbra de. Produção e Apropriação do Espaço Urbano: a verticalização de Belém. 1992. Tese (Doutorado em Geografia Humana). Faculdade de Filosofia Letras e Ciências Humanas. Universidade de São Paulo, São Paulo.

PADILHA, Valquíria. Shopping Center: a Catedral da Mercadoria. São Paulo: Editora Boitempo, 2006.

PINTAUDI, Silvana Maria. Templo da Mercadoria. Estudo sobre os Shopping-Centers do Estado de São Paulo. 1989. Tese (Doutorado em Geografia). Faculdade de Filosofia Letras e Ciências Humanas. Universidade de São Paulo, São Paulo.

O Shopping Center no Brasil: Condições de Surgimento e Estratégias de Localização. In: Shopping Centers: Espaço, Cultura e Modernidade nas Cidades Brasileiras. Org: Silvana M. Pintaudi e Heitor Frúgoli Jr. - São Paulo: Editora Unesp, 1992.

PINTAUDI, Silvana Maria. FRÚGOLI JR. Heitor. (org.) Shopping Centers: espaço, cultura e modernidade nas cidades brasileiras. São Paulo: Editora da Universidade Estadual Paulista, 1992.

RUIZ, João Antonio Martinez. Shopping Center: segregação, exclusão e inclusão. Análise a partir de bairros residenciais em Presidente Prudente-SP. 2004. Dissertação (Mestrado em Geografia). Universidade Estadual Paulista - Faculdade de Ciências e Tecnologia, Campus de Presidente Prudente - SP

SANTOS, Milton. Por uma economia política da cidade. São Paulo: Hucitec, 1994.

SANTOS JUNIOR, Wilson Ribeiro dos. "Shopping Center: Uma Imagem de Espelhos". In: Shopping Centers: Espaço, Cultura e Modernidade nas Cidades Brasileiras. Org: Silvana M. Pintaudi e Heitor Frúgoli Jr. - São Paulo: Editora Unesp, 1992.

SERPA, Vera Schrader. O Sub-Centro Comercial do Méier: contribuição do estudo da estrutura varejista intra-urbana derivada do processo de descentralização da metrópole do Rio de Janeiro. 1991. Dissertação (Mestrado em Geografia). Universidade Federal do Rio de Janeiro, Rio de Janeiro.

SHOPPING CATUAÍ. Sobre o Shopping. 2014. Disponível em:

<http://www.catuaishopping.com.br/Shopping.aspx > Acesso em 22 de Nov. de 2014.

SHOPPING CENTERS. Revista Veja. São Paulo, nº 742, p. 77, 1998.

SOUZA, Eduardo. "A ideia do shopping center fechado completa 60 anos (e prepara sua aposentadoria)". Maio de 2013. Disponível em: http://www.archdaily.com.br/77676/a- 
ideia-do-shopping-center-fechado-completa-60-anos-e-prepara-sua-aposentadoria> Acessado 26 Nov. de 2014.

SOUZA, Maria Adélia A. de. A Identidade da Metrópole: a Verticalização de São Paulo. São Paulo: EDUSP, 1994.

A Identidade na Metrópole: a verticalização em São Paulo. 1989. Tese (Doutorado em Geografia). Faculdade de Filosofia, Letras e Ciências Humanas. Universidade de São Paulo, São Paulo.

SPÓSITO, Maria Encarnação Beltrão. O Centro e as Formas de Expressão da Centralidade. In: Revista de Geografia, São Paulo: Universidade Estadual Paulista, UNESP, Vol. 10, 1991. Multi(poli)centralidade urbana em Bauru, São José do Rio

Preto e Presidente Prudente. Projeto de Pesquisa Integrada, Presidente Prudente, 1996.

VILLAÇA, Flavio. Espaço Intra-Urbano no Brasil. São Paulo: Studio Nobel: FAPESP: Lincoln Institute, 2001. 